\title{
Integrating High-Resolution Datasets to Target Mitigation Efforts for Improving Air Quality and Public Health in Urban Neighborhoods
}

\author{
Vivek Shandas *, Jackson Voelkel, Meenakshi Rao and Linda George \\ Toulan School of Urban Studies and Planning, Portland State University, 1825 SW Broadway, Portland, \\ OR 97201, USA; jvoelkel@pdx.edu (J.V.); mrao@pdx.edu (M.R.); georgel@pdx.edu (L.G.) \\ * Coresspondence: vshandas@pdx.edu; Tel.: +1-503-725-5222 \\ Academic Editor: Jason Corburn \\ Received: 30 April 2016; Accepted: 27 July 2016; Published: 5 August 2016
}

\begin{abstract}
Reducing exposure to degraded air quality is essential for building healthy cities. Although air quality and population vary at fine spatial scales, current regulatory and public health frameworks assess human exposures using county- or city-scales. We build on a spatial analysis technique, dasymetric mapping, for allocating urban populations that, together with emerging fine-scale measurements of air pollution, addresses three objectives: (1) evaluate the role of spatial scale in estimating exposure; (2) identify urban communities that are disproportionately burdened by poor air quality; and (3) estimate reduction in mobile sources of pollutants due to local tree-planting efforts using nitrogen dioxide. Our results show a maximum value of $197 \%$ difference between cadastrally-informed dasymetric system (CIDS) and standard estimations of population exposure to degraded air quality for small spatial extent analyses, and a lack of substantial difference for large spatial extent analyses. These results provide the foundation for improving policies for managing air quality, and targeting mitigation efforts to address challenges of environmental justice.
\end{abstract}

Keywords: air pollution; dasymetric; urban; tree-planting

\section{Introduction}

Unhealthy atmospheric conditions in urban environments are remarkably costly. Air pollutants from anthropogenic combustion processes pose a serious risk to public health and the environment [1], with the costs of exposure impacts estimated at over $\$ 220$ billion annually in the US [2]; and an estimated 50 to 120 thousand premature deaths [3]. Recent evidence also suggests that long-term exposure to air pollution, especially respirable particles, can have profound impacts on cardiovascular risk factors, including artherosclerosis, hypertension, ischemic heart disease, and cardiovascular mortality [4,5]. Korek et al. (2015) [6], for example, found that long-term exposure at relatively low levels to nitrogen oxides (NOx and particulate matter $\left(\mathrm{PM}_{10}\right)$-two air pollutants created by combusting fossil fuels-from local traffic is significantly correlated to stroke. With the world's population increasingly living and breathing in cities, mortality and morbidity rates due to air pollution are sure to rise, especially in rapidly industrializing countries.

In the US, urban atmospheres are managed under a regulatory framework that assesses air quality at regional and national scales. However, current research in epidemiology [7,8], air quality [9-12], and environmental justice [13-15] clearly show that the issues of air pollution must be addressed at the neighborhood scale $(\leqslant 1 \mathrm{~km})$, because local hotspots that impact human vulnerability do not show up in regional analyses. Vulnerability, in this sense is the combined impact of exposure to degraded air quality and social conditions that can reduce the capacity to cope [16,17]. Additionally, regional assessments of human exposure, vulnerability, and coping with these adverse atmospheric threats ignore the 
role of municipal planning agencies, social drivers, and governance structures in exacerbating or ameliorating these threats [18,19], and limit the involvement of cities and neighborhood groups in improving urban health and well-being. For example, city managers and other decision-makers are expanding vegetation campaigns to improve air quality without a framework for understanding who is most impacted by degraded environmental conditions or, alternatively, those benefiting from these plantings. Thus, to substantially improve urban health and well-being, now and into the future, decision-makers need to simultaneously understand the distribution of air pollutants, identify the communities most exposed, and assess the effectiveness of mitigation strategies, such as tree-plantings, at the local scale.

Such an understanding about the drivers, impacts, and effective mitigation efforts, however, pose several challenges to a scientifically defensible and replicable approach. One formidable challenge is the heterogeneity of the urban environment, which results in high spatial variability of urban air pollution and, as a result limits accurate measurements of air pollutants at finer spatial scales [20,21]. Another significant limitation is that datasets for understanding who is being exposed to degraded air quality rely on data that assume uniform distribution of human populations at small spatial scales. For example, datasets on the distribution of human populations and socio-demographics are freely available through the US Census, and contain geographic extents that assume a distribution of people evenly across a spatial unit (i.e., block, block group, tract, county, etc.). Earlier studies examining linkages between human health and air pollutants, while increasingly commonplace, use these US Census datasets, often at the county [22,23], or tract [24] levels, which, while suitable for statewide or national estimates, fall short for characterizing local exposure.

We posit that improving the resolution of exposure estimations requires three essential steps: (1) understanding the heterogeneous distribution of human populations in cities; (2) explicitly assessing the spatial variation of urban air pollutants; and (3) aligning the heterogeneous distribution of urban populations with a spatially commensurate highly-resolved air quality data $[7,25,26]$. The emergence of highly-resolved air quality monitoring techniques [27] and advances in spatial analysis offer a timely and promising approach to understanding those factors that mediate exposure to degraded environmental conditions. From the perspective of polices to improve human health and well-being, integrating high resolution datasets is a first step to identifying and targeting locations for the application of promising mitigation interventions.

In this study, we build on spatial analysis techniques for assessing air quality that can support city managers to better estimate the number of people exposed to degraded air quality, as well as to assess the extent to which one local mitigation strategy-tree-plantings—are effective in reducing exposure. Our approach begins by adapting and integrating two existing spatial analysis techniques to allocate urban population-cadastral and dasymetric mapping. We refer to our technique as a cadastrally-informed dasymetric system (CIDS): cadastral, because our maps employ high-resolution tax lot/parcel data which contain information on where residences are located and not located, such as on roadways, parks, factories, and other non-residential land uses; and dasymetric because we use disaggregated census-based population enumeration/aggregation geometries. Together-the residential tax lot to identify specific locations in our study area, and disaggregation of population estimates-provides an accurate distribution of the population. The population distribution is then combined with highly spatially-resolved nitrogen dioxide $\left(\mathrm{NO}_{2}\right)$ data-an effective marker for anthropogenic combustion-related pollution-from a previously-developed observationally-based land-use regression model. These datasets help us to address three research questions: (1) What are differences in the exposure between household derived estimates of exposure to air pollution and those at different (or larger) spatial geographies? (2) Which locations and communities have the greatest exposure to air pollution, using $\mathrm{NO}_{2}$ as an indicator? (3) To what extent are neighborhood tree-planting campaigns effective in mitigating exposure to degraded air quality?

Our research questions address several salient concerns about managing air quality in cities, including improving the spatial resolution of characterizing pollutants, the extent to which different 
demographic populations are disproportionally exposed to degraded air; and what short-term mitigation strategies show promise for improving local environmental conditions. To address these questions, we apply the CIDS approach to identify the location of communities most impacted by urban air pollution in the Portland Metro area. Next, we examine the extent to which Washington County's (one of the three counties comprising our study area) re-vegetation efforts are directly impacting human health through the reduction of $\mathrm{NO}_{2}$ associated with tree canopy. Clean Water Services (CWS), the wastewater utility for Washington County, has invested in a major re-vegetation campaign since 2004, as part of a federal mandate. Now, over ten years after implementation, CWS has planted over 2 million trees, shrubs, and bulbs across 15,000 acres of land and several 100 of miles of riparian habitat, and anticipates another one million plantings in the coming years. Although our case study is in Portland Metro and Washington County, it is generally applicable to any part of the world, so long as comparable data exist.

\section{Materials and Methods}

\subsection{Study Area}

Our study area is the Portland Metropolitan Area (PMA), a mid-size urban area covering $7967 \mathrm{~km}^{2}$, with a population of $\sim 1.5$ million (2013), located in the state of Oregon, in the Northwestern USA. It is situated at $45.52 \mathrm{~N}, 122.68 \mathrm{~W}$, and has a temperate climate with relatively dry summers. The PMA is an ideal location for such a study for three reasons: (1) we have an abundance of highly resolved data for the region; (2) the tree canopy is diverse and, unlike many other cities, contains an extensive amount of tree canopy; and (3) community groups are actively in the process of expanding the tree canopy, although identifying locations for improving population health still requires further efforts. Approximately $29.4 \%$ of the PMA is under tree canopy. Mobile air pollutants, such as $\mathrm{NO}_{2}$, vary between summer and winter in Portland (summer and winter $2013 \mathrm{NO}_{2}$ averages were $7.5 \mathrm{ppb}$ and $11.4 \mathrm{ppb}$, respectively). Our study area includes Washington County, which is an area covering approximately $1882 \mathrm{~km}^{2}$, and is composed of both urban and rural areas. It is the fastest growing county in Oregon, with an estimated 500,000 people moving into the county by 2020 . Approximately $26.7 \%$ of Washington County is under tree canopy.

\subsection{Data Used and Analytical Process}

We draw on several different datasets (Table 1) to address our research questions. Our overall methodology has three main steps: (i) using CIDS to develop a highly spatially-resolved population distribution map; (ii) developing a detailed exposure surface at three different spatial scales and evaluating differences-by exposure surface, we mean the distribution of $\mathrm{NO}_{2}$ and the total population who have an increased likelihood of exposure; and (iii) apply the CWS tree plantings at 5, 15, and 35 year growth projections, together with the reduction factor for the tree canopy, to assess the number of people benefiting from these plantings. Each of these steps is described in detail in the following sections.

Using these datasets we were able to evaluate the level of exposure to an air pollutant $\left(\mathrm{NO}_{2}\right)$ at three different scales. The first, using CIDS, assigns a population total at a tax-lot scale, and is described in further detail below. The second scale of analysis employs the US Census Block Group. The majority of Census Block Groups in the region contain between 600 and 3000 people, and vary in their geographic extent. We also used the US Census Tract, which contains between 1200 and 8000 people. The number of people in each of these geographic units was assessed in terms of potential exposure to the worst air quality and distance from the nearest highway. The results provide a means for evaluating the extent to which the characterization of geographic units affects potential exposure. 
Table 1. Description and source of data sets used in analysis.

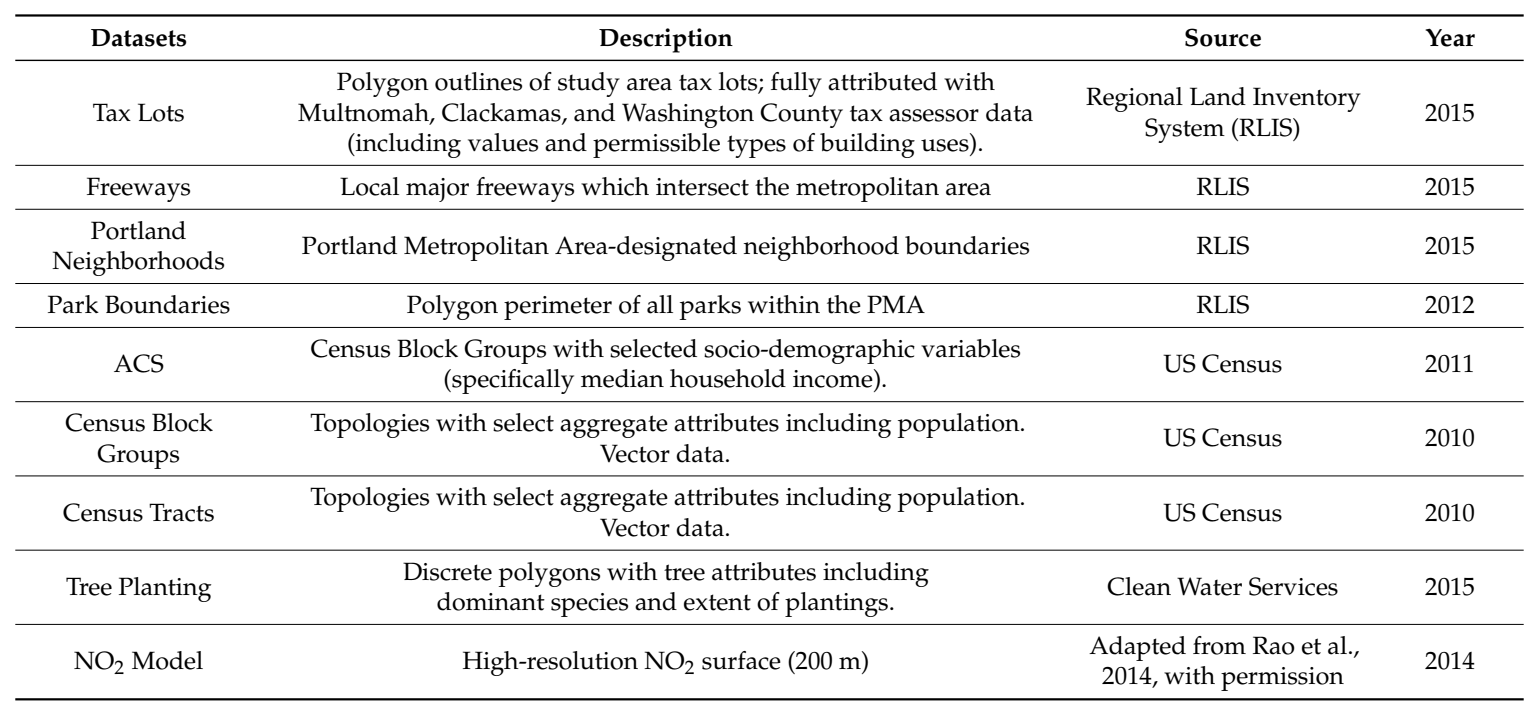

\subsubsection{Cadastrally-Informed Dasyametric System (CIDS) for Population}

Dasymetric mapping provides a means for higher accuracy areal population estimates through a process of disaggregation of enumeration units (e.g., United States Census Bureau Tracts or Block Groups) [28]. This disaggregation is necessary for high-accuracy analyses as it helps to combat the negative effects of the modifiable areal unit problem (MAUP) [29]. MAUP has been well documented in the literature on the exposure to environmental hazards as an issue occurring with non-uniform aggregation/enumeration units wherein results can be significantly different depending on which units of measurement are chosen for analysis [30-32]. By "removing" population data from the constraints of Census geometries, we are able to examine them on a more human and realistic house-by-house level in contrast to an assumption of uniform distribution across a specified geography.

To construct a dasymetric map of the Portland Metro population, we use the tax lot (also known as a parcel or household) as the unit for allocating the population. In contrast to larger geographies available through the US Census (i.e., Census Block Group, Tract, County, etc.), where the population is assumed to be evenly distributed, the tax lot allocation can identify a more precise location and enumeration of the people residing at each tax lot. First, using 2015 tax lot data embedded with zoning and tax assessor information from the regional municipal government agency, Metro, we identify residential areas within each US Census block group (CBG) where the population can be allocated. We did this by filtering the 2015 tax lot dataset to create a new dataset containing only residential parcels. Using spatial analysis software (ArcMap Release 10.2, Redlands, California, ESRI Inc., Redlands, CA, USA), we extracted five categories of parcels using the embedded tax assessor data: Single Family Residential (SF), Multi-family Residential (MF), Rural, Agricultural, and Forested. Further processing of the filtered data resulted in a 'Building Value' measure that described whether the assessed monetary value of the building was zero (implying no home existed on the parcel) or a value greater than zero, suggesting a building was present. Any tax lots with a value of zero were removed from the list, along with those officially assessed as "Vacant." Tax lots that spanned CBG boundaries were assigned to the CBG which included the centroid of the tax lot.

Since our tax assessor's dataset for MF tax lots do not include the number of units, we developed a technique for attributing the number of people to specific units. To estimate the number of housing units in each MF we conducted a one-question phone survey that asked 60 randomly selected MF property managers how many units comprised their building. We developed an ordinary least squares (OLS) linear regression analysis using R statistical software (R Core Team, Version 2.15.3, Vienna Austria, R Foundation for Statistical Computing), to predict the number of housing units 
(based on the phone survey), with readily-available variables, including the land and building values (Equation (1)).

$$
\text { Predicted Housing Units MF }=3.261+1.573 \mathrm{e}^{-5} \times \mathrm{LV}+8.858 \mathrm{e}^{-6} \times \mathrm{BV}
$$

where:

$$
\begin{gathered}
\mathrm{LV}=\text { Value in USD of land within tax lot } \\
\mathrm{BV}=\text { Value in USD of buildings within tax lot }
\end{gathered}
$$

The results of the phone survey and our predicted housing units provided a high level of predictability $\left(r^{2}=0.97\right)$, which suggested that we can apply our results to all MF in the study region. OLS regression was employed as the initial exploratory analysis technique due to its simplicity and common usage - the high performance displayed left the authors satisfied that the method was sufficient and other more complex models did not need to be introduced. Using Equation (1), we calculated the predicted housing value for all MFs, and summarized for the CBG. The population to be assigned to each MF tax lot was then determined (Equation (2)), and used to develop a population density (people per square foot) estimate for both SF and MF polygons:

$$
\text { Population }_{\text {Tax }} \text { Lot, } \mathrm{CBG}=\left(\text { Predicted Housing Unit } \text { Taxlot }_{\text {Predicted Housing Unit }} \text { CBG }\right) \times \text { POP }_{\text {CBG }}
$$

The population density was converted to a one square foot resolution grid wherein each pixel contained a single value representing population per square foot. The grid, or raster, dataset provided a computationally-efficient method for estimating population since the sum value of all pixels in the grid represented a population estimate in number of people.

\subsubsection{Estimating Exposure Surfaces}

\section{Air Quality Assessments}

Air quality was assessed using $\mathrm{NO}_{2}$ as a marker. $\mathrm{NO}_{2}$ is a ubiquitous urban air pollutant, produced by anthropogenic combustion processes. It is also one of the six US EPA criteria pollutants, and is the precursor to two other criteria pollutants, namely ozone and $\mathrm{PM}_{2.5}$ and, thus, serves as an excellent marker of air quality. The World Health Organization, in addition, recommends a threshold of $\mathrm{NO}_{2}$ below $40 \mu \mathrm{g} / \mathrm{m}^{3}$ [33]. In most urban areas in the US, combustion engines in automobiles are the biggest source of $\mathrm{NO}_{2}$. This $\mathrm{NO}_{2}$, emitted along traffic corridors is dispersed through turbulence and wind. Since it is a reactive gas, it also reacts to produce secondary pollutants (ozone) [34,35]. Studies find that $\mathrm{NO}_{2}$ levels are highest near the source, and then decay away from it, reaching background levels 200-400 $\mathrm{m}$ away [36].

We used the $\mathrm{NO}_{2}$ model developed by Rao et al. (2014) [37] (Equation (3)) for the Portland Metro area to assess air quality. Rao et al. were able to explain $80 \%$ of the variation in $\mathrm{NO}_{2}$ using a model that employed variables such as annual average daily traffic (AADT) and tree cover.

$$
\begin{aligned}
& \mathrm{NO}_{2}(\mathrm{i})=7.7+1.1 \times 10^{-8} \times \text { FWY_AADT } 1200, \mathrm{i}+6.5 \times 10^{-4} \times \mathrm{MAJ}_{-} \mathrm{ART}_{500, \mathrm{i}}+1.7 \times 10^{-3} \times \\
& \text { ARTERIES }_{350, \mathrm{i}}+1.8 \times 10^{-8} \times \text { STREETS }(P O P)_{800, \mathrm{i}}+1.0 \times 10^{-3} \times \text { RAILS }_{250, \mathrm{i}}- \\
& 1.0 \times 10^{-2} \times \text { ELEVATION }_{\mathrm{i}}+1.4 \times 10^{-5} \times\left(\text { ELEVATION }_{\mathrm{i}}\right)^{2}-5.73 \times 10^{-6} \times \\
& \text { TREES }_{400, \mathrm{i}}+1.1 \times 10^{-4} \times \mathrm{X}_{-} \text {DIST }_{\mathrm{i}}
\end{aligned}
$$

Adj $R^{2}=0.80$, validation $R M S E=2.2$

where: 


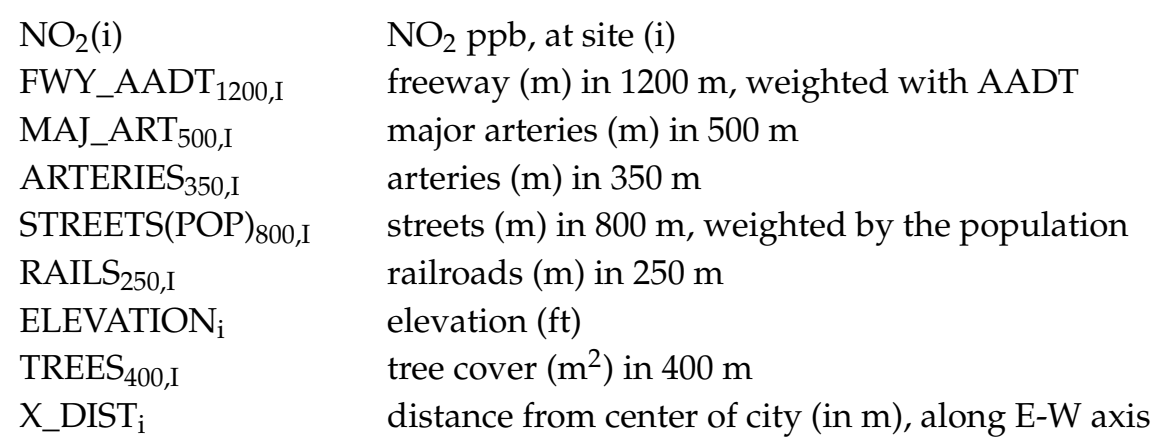

The model was created from direct observational data detected at 144 monitoring stations throughout the PMA, using passive Ogawa samplers. For more details on the field campaign and model development, please see Rao et al. (2014) [37]. As can be seen from the model, each hectare of tree cover within a $400 \mathrm{~m}$ radius of a site is associated with a $0.6 \mathrm{ppb}$ reduction in $\mathrm{NO}_{2}$, holding all other variables constant. The model was applied to a $200 \mathrm{~m}$ point grid, which was then rasterized for faster calculations.

Integrating Population Estimates with Air Quality Assessments

We first identified all neighborhoods in Portland that had the most degraded air quality, which was identified as the worst quintile of nitrogen dioxide (13-24 ppb), based on the $\mathrm{NO}_{2}$ model. Next, to evaluate the effect of spatial scale of population estimates on potential exposure to $\mathrm{NO}_{2}$, we compared the air quality raster with the following population estimates: the tax lot using the CIDS approach, the US Census block group (as a population density raster), and the US Census track (as a population density raster) geographies. Population estimates for each geography were calculated using a zonal statistics technique (ArcMap Release 10.2, Redlands, California, ESRI Inc.). The result from our zonal statistics technique summarizes the population density value for all pixels that are within an area of interest (e.g., highway, highest concentrations of $\mathrm{NO}_{2}$, etc.). By comparing across the three geographies using the $\mathrm{NO}_{2}$ raster's 80th percentile as a specific area of interest, we can estimate the number of people who are potentially exposed to the largest concentrations of $\mathrm{NO}_{2}$.

In addition to looking at the potential neighborhood-level exposure, we further leveraged the CIDS population distribution to identify residences within $75 \mathrm{~m}$ and $150 \mathrm{~m}$ of regional highways (e.g., high traffic corridors). Current epidemiological research suggests that living in proximity to traffic corridors can create a disproportionate risk from traffic related pollution, including increasing incidence of asthma [38,39]; lung function deficit [40]; and cardiovascular problems [41]. Correctly identifying the population and demographics of people residing in pollution hot-spots such as traffic corridors can inform city-level policies on zoning (example, locating elementary schools $>200 \mathrm{~m}$ away from freeways). Further, given the long history of neighborhood involvement in the study area, we also identified the neighborhoods in the PMA that lie in the highest quintile of $\mathrm{NO}_{2}$. Information about neighborhood $\mathrm{NO}_{2}$ can potentially engage and empower citizens with the worst $\mathrm{NO}_{2}$ levels to address the issue by implementing local mitigation strategies. Though the worst quintile of $\mathrm{NO}_{2}$ in our study area is highly associated with high traffic areas, the $75 \mathrm{~m}$ and $150 \mathrm{~m}$ areas of interest are drastically smaller and represent those locations where populations have been shown to have highest levels of health impacts.

\subsubsection{Case Study: Assessing the Mitigation of $\mathrm{NO}_{2}$ by CWS Tree Plantings}

Washington County's Clean Water Services, over the last decade, has planted trees at 162 planting sites across Washington County, Oregon. A typical planting site is small, covering an average of $0.02 \mathrm{~km}^{2}$. Although the main purpose of the plantings was to improve water quality, the small-scale nature of each planting makes it ideal to assess the potential of local mitigation strategies in improving 
air quality. CWS had a spatially explicit dataset with locations and extent of canopy-based restoration sites going back to 2004 .

Since tree planting occurs when they are saplings we used existing literature [42] to model canopy growth associated with plantings at 5, 15, at 35 year intervals. Growth rates used for different functional types of plantings can be found in Table 2. Tree-related $\mathrm{NO}_{2}$ reduction on a site-by-site basis was assessed at these future intervals using Equation (3), and the number of people benefiting from a reduction in $\mathrm{NO}_{2}$ was estimated using the tax lot derived CIDS approach. Since we are unable to discern where population growth will occur in Washington County in the coming decades, our approach kept the population fixed at the 2010 levels over the entire 35 year period, which makes our estimates conservative in terms of the number of people experiencing benefits from the canopy campaigns. We note that, as population grows, the $\mathrm{NO}_{2}$ will also increase, and ours are likely conservative estimates of populations who are likely to be exposed to degraded air pollution.

Table 2. Tree planting associated to functional type and increases in canopy cover (Washington County, OR, USA).

\begin{tabular}{cccc}
\hline Location Functional Type & 5 Years & 15 Years & 35 Years \\
\hline Emergent Marsh & $0 \%$ & $0 \%$ & $0 \%$ \\
Forested Wetland & $25 \%$ & $50 \%$ & $85 \%$ \\
Oak Woodland & $5 \%$ & $25 \%$ & $50 \%$ \\
Riparian Forest & $25 \%$ & $50 \%$ & $85 \%$ \\
Riparian Forest Low Density & $25 \%$ & $45 \%$ & $65 \%$ \\
Scrub shrub & $25 \%$ & $40 \%$ & $75 \%$ \\
Scrub Shrub Low Density & $20 \%$ & $35 \%$ & $55 \%$ \\
Upland Buffer & $25 \%$ & $50 \%$ & $85 \%$ \\
Upland Forest & $25 \%$ & $50 \%$ & $85 \%$ \\
Wet Prairie & $0 \%$ & $0 \%$ & $0 \%$ \\
\hline
\end{tabular}

\section{Results}

We divide our results into three sections, the first two of which describe the outcome of the CIDS approach, including the difference between our approach and those used in other estimates of potential exposure, and the role of tree plantings in reducing exposure. The final section addresses the implications of our study and caveats in applying these techniques to other cities and regions.

\subsection{Assessing Population Density and Potential Exposure Using CIDS}

Dasymetric maps show promise in assessing exposure and risk because they provide a highly-resolved description about the underlying population density by using ancillary data for disaggregating population estimates, while remaining consistent with the census genealogy [43]. Arguably, accurate population density estimates are essential in assessing potential population exposure to the highly spatially variable pollutants, such as $\mathrm{NO}_{2}$, that are very common in urban areas. Our CIDS approach combined dasymetric allocation techniques with high-resolution cadastral land use and ownership data, to develop a highly spatially resolved ( $1 \mathrm{ft}, 0.305 \mathrm{~m})$ map of population density in the PMA (Figure 1a).

Our results reveal that applying the CIDS approach for allocating urban populations in the PMA changes the geographic extent of possible exposure locations. For example, the CIDS indicates that the total population of the PMA is distributed across $2159 \mathrm{~km}^{2}$, while methods of uniform population distribution at the county-scale would allocate the population across the entire tri-county area of $7967 \mathrm{~km}^{2}$. As a result, the CIDS approach would distribute population over just a quarter of the tri-county area $(27 \%)$, while leaving $73 \%$ of the tri-county area non-residential. Similarly, for Washington County, CIDS allocates the population to $602 \mathrm{~km}^{2}$ as compared to the county area of $1882 \mathrm{~km}^{2}$, leaving $68 \%$ of the entire area of the county's total land area unpopulated. 


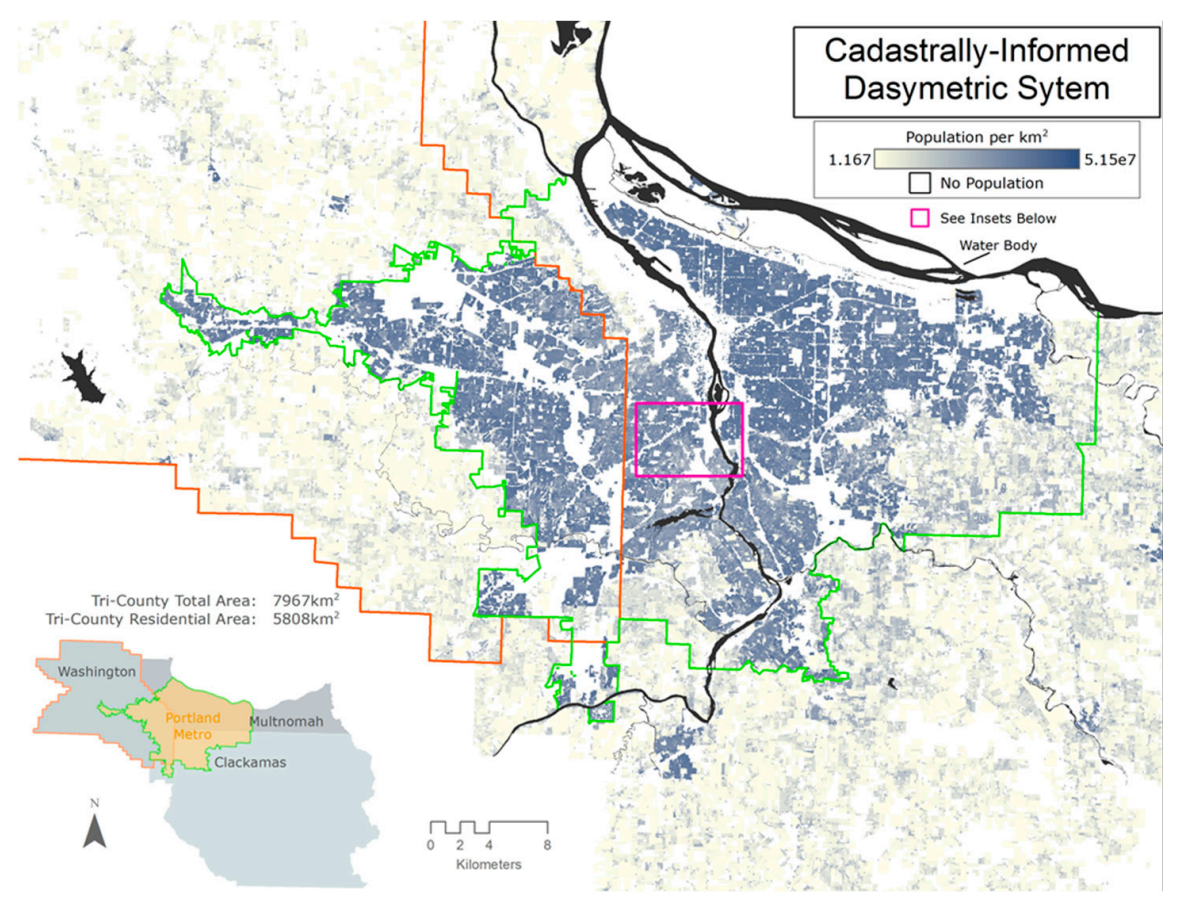

(a)

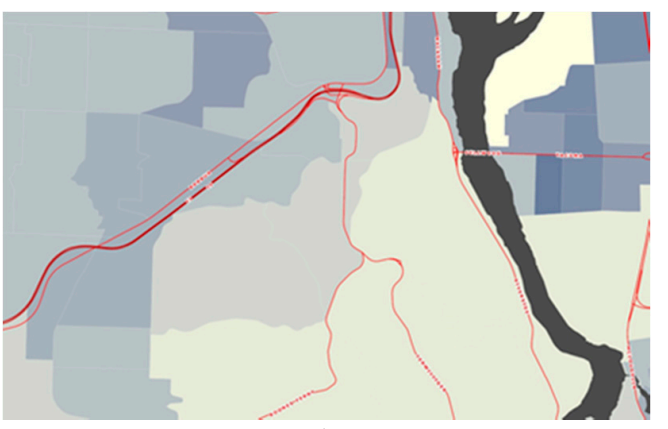

(b)

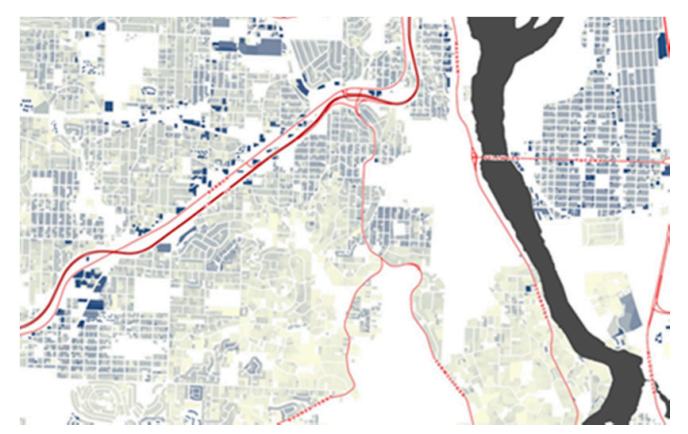

(c)

Figure 1. (a) (Above) the cadastrally-informed dasymetric map of the Portland Metropolitan region; (b) (Left) choropleth map of population density (population of Census Block Group divided by area of Census Block Group); and (c) (Right) dasymetric map of population density.

A visual description between the two approaches provides additional support for moving toward a tax lot-based approach to likely exposure estimates via population density (Figure 1b,c). If, for example, the population is evenly distributed across a CBG that is adjacent to a source of air pollution (e.g., a high traffic corridor), then everybody in that CBG is assumed to be exposed to that source of pollution. Since a CBG can range from a few square kilometers in highly populated areas to hundreds of square miles in rural areas, assuming uniform exposure, given the spatial variability of urban air pollution, is inaccurate. In addition, identifying MF tax lots that are highly affected by air pollution can also help to target mitigation efforts, since such practices are costly and often unfeasible at large geographies.

We can expect, then, that potential exposure estimates based on methods, like CIDS, which account for where people actually live relative to sources of pollution, will provide greater accuracy for identifying populations most impacted by degraded air quality. To that end, we estimated the number of people exposed to air pollution (i) using $\mathrm{NO}_{2}$ as a marker for anthropogenic combustion-related pollution; (ii) the distance from freeways as a marker of traffic-related air pollution (high traffic corridor) 
using three geographic scales-tax lot (using our CIDS approach), US Census Block Groups (CBGs) (as a population density raster dataset), and US Census Tract (as a population density raster dataset).

\subsubsection{Estimating Population- $\mathrm{NO}_{2}$ Worst Quintile}

Based on the CIDS and a highly-resolved $\mathrm{NO}_{2}$ surface [37] (Figure 2), we estimated that $\sim 330,500$ people (18\% of the Portland Metro population) are exposed to the worst quintile of $\mathrm{NO}_{2}$ pollution (13-24 ppb). Census Geography rasters were measured in the same manner by overlaying the area of interest over a rasterized choropleth of population density for both CBG and Census Tracts and calculating population values for only those specific pixels. Assuming the standard uniform population distribution over a CBG, the estimate of the exposed population is $\sim 326,700$, or about a $1 \%$ underestimate compared to the CIDS, while using census tract scale population data results in an estimate of 329,700 people exposed to the worst quintile of $\mathrm{NO}_{2}$, an estimate comparable to the CIDS (Table 3). Similarly, when examining the number of people exposed to the worst decile of $\mathrm{NO}_{2}$ (15-24 ppb), CIDS estimates 177,440 people, CBGs estimate 179,700 people, a $1 \%$ overestimate compared to CIDS, while the census tract-level population estimates result in a $2 \%$ overestimation compared to CIDS.

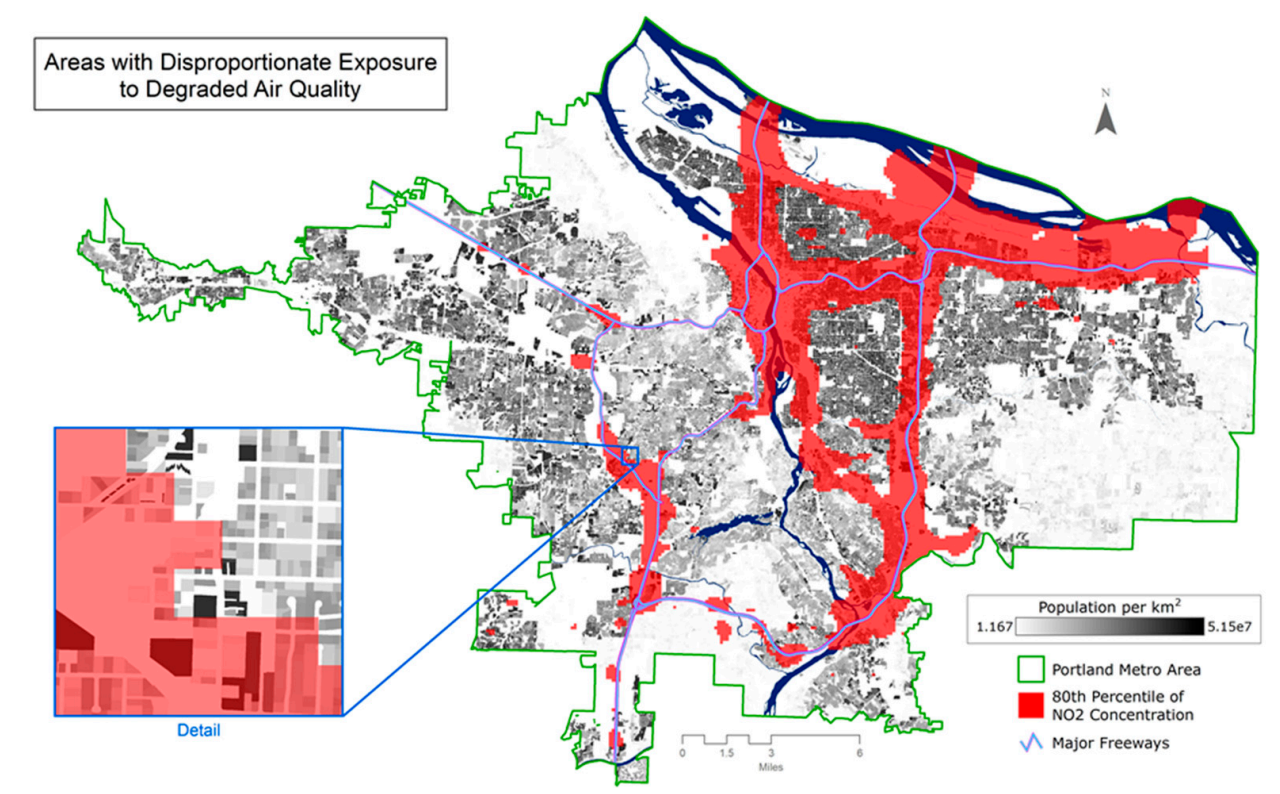

Figure 2. Distribution of the highest concentrations of $\mathrm{NO}_{2}$ in areas with the greatest number of people.

Table 3. Comparison of the total population exposed to degraded air quality using three geographic extents, and two distances from freeways.

\begin{tabular}{|c|c|c|c|c|}
\hline \multirow[b]{2}{*}{ Exposure Unit } & \multicolumn{2}{|c|}{ Number of People Exposed to $\mathrm{NO}_{2}$} & \multicolumn{2}{|c|}{ Number of People Living Near Highways } \\
\hline & $\begin{array}{c}\text { Worst Quintile } \\
\text { (13-24 ppb) }\end{array}$ & $\begin{array}{l}\text { Worst Decile } \\
\text { (15-24 ppb) }\end{array}$ & $75 \mathrm{~m}$ & $150 \mathrm{~m}$ \\
\hline (CIDS) Tax Lot & 330,500 & 177,400 & 12,700 & 42,000 \\
\hline CBG & $326,700(-1 \%)$ & $179,700(+1 \%)$ & $34,300(+169 \%)$ & $63,700(+52 \%)$ \\
\hline TRACT & $329,700(-0 \%)$ & $181,400(+2 \%)$ & $37,800(+197 \%)$ & $69,600(+66 \%)$ \\
\hline
\end{tabular}

\subsubsection{Estimating Population-Highway Corridors}

While the estimates with the CBGs and tracts may not substantially differ from the CIDS approach, in part because they are derived from the same data, an analysis of exposure from high traffic corridors, or highways, suggests an orders of magnitude difference in exposure. Based on existing 
literature, populations living near highway corridors are disproportionately at risk for asthma and other respiratory problems [21,38,44,45]. Using the CIDS and a highway corridor buffer of $75 \mathrm{~m}$, we find that 12,700 people are at risk of traffic-induced respiratory problems. CBGs overestimate the population at risk by $169 \%$, and tracts overestimate by 197\% (Table 3). The CIDS in $150 \mathrm{~m}$ corridors, estimates 42,000 people at risk of traffic-induced respiratory problems, while CBGs overestimate the population at risk by $52 \%$, and tracts overestimate by $66 \%$ (Table 3 ).

\subsection{To What Extent Are Neighborhood Tree Planting Campaigns Effective in Mitigating Exposure to Degraded Air Quality?}

Many cities and neighborhoods are undertaking tree plantings, to beautify neighborhoods as well as to mitigate air pollution and urban heat. As part of an effort to understand the extent to which these local mitigation measures can improve degraded air quality, we evaluated the contribution to local air quality improvement within Washington County. Based on the results of an earlier study (Rao et al., 2014) [37], we determined that each of the planted sites could potentially be associated with a reduction in $\mathrm{NO}_{2}$ for up to $400 \mathrm{~m}$ from the site. Our results describe the number of people that are affected by the CWS tree plantings based on the canopy cover at 35 year maturity (Figure 3). Using the CIDS, and maintaining 2010 population, we find that 142,300 Washington County residents will experience a non-zero reduction in $\mathrm{NO}_{2}$. We further estimated that $\sim 9600$ Washington County residents would experience a $2 \%-9 \%$ reduction in $\mathrm{NO}_{2}$ five years after planting, increasing to $\sim 11,800$ residents 15 years after planting, and $\sim 20,500$ would benefit from a $2 \%-9 \%$ reduction in $\mathrm{NO}_{2} 35$ years after planting. The small size of a typical planting site and the small spatial extent over which tree canopy is seen to affect $\mathrm{NO}_{2}$ concentrations highlight the need for highly spatially resolved population, pollutant, and canopy data.

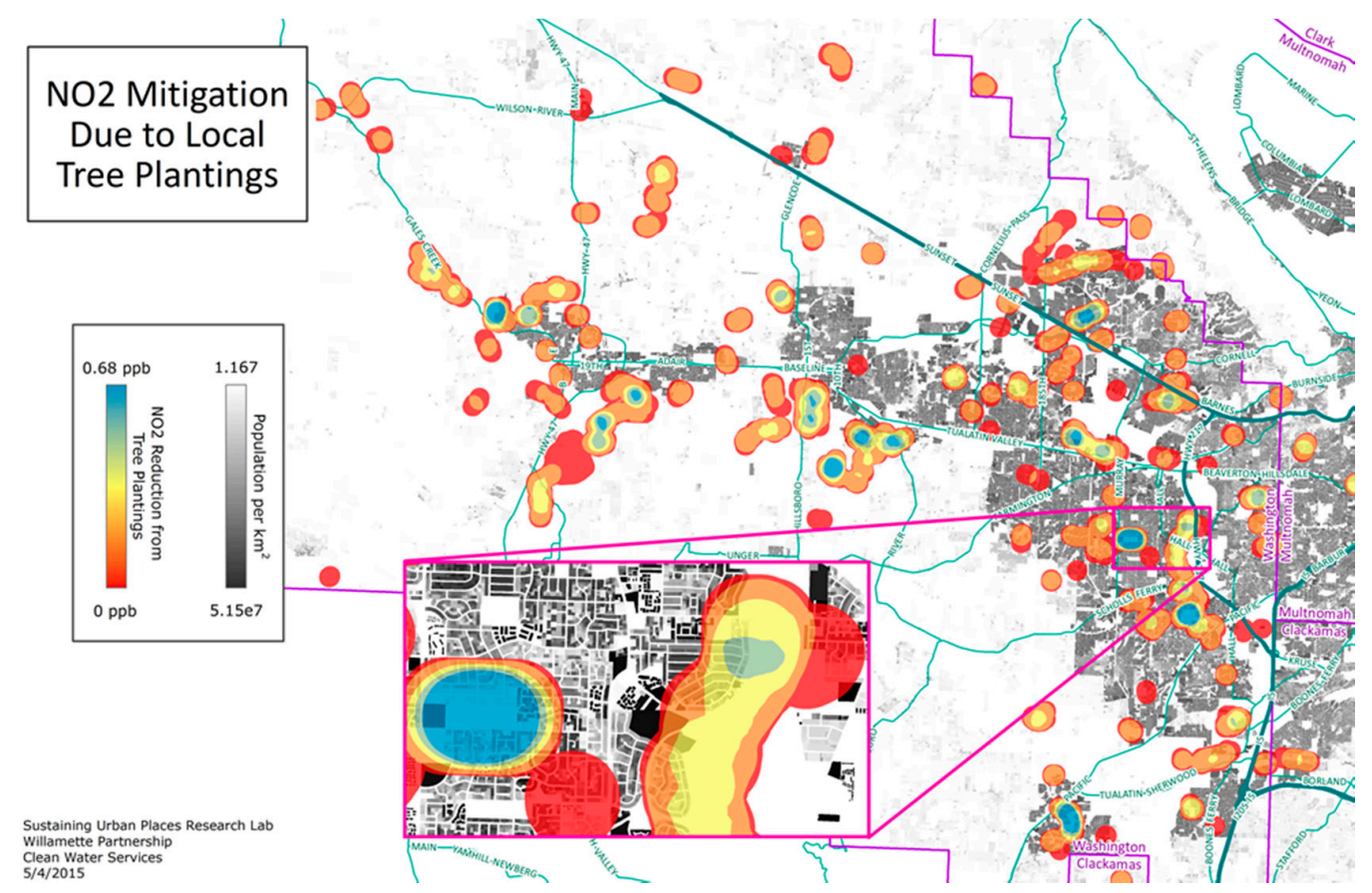

Figure 3. $\mathrm{NO}_{2}$ reduction associated with Clean Water Service (CWS) planting sites (35 year projection).

These results suggest that even in cases where an organization may not have directly considered the benefit of tree plantings to the immediately-adjacent populations, our CIDS approach provides a means for accounting for those who directly benefit. In targeting future tree plantings-a general program that is gaining increasingly popularity among municipalities across the globe- knowing how 
many people may benefit can be considered a direct measure of success. Certainly, decision-makers, planners, and public health advocates can assess the extent to which specific mitigation efforts has the greatest benefit to the largest number of people.

\section{Discussion}

The difference in population allocation strategies between US Census and CIDS alone provides one argument for the consideration of highly resolved population density estimations. Although only minor differences were detected between the CBG and tract estimates of population, and the CIDS, our analysis suggests considerable variation in potential exposure in the highway corridors. We observe that the smaller unit for assessing exposure, the greater the difference in estimates from CBG and tract estimates. The overestimation of exposure by CBGs and tracts as compared to the CIDS when estimating population within $75 \mathrm{~m}$ and $100 \mathrm{~m}$ of highways can be explained by the population allocation strategies used in these methods. Since the CBG and tract assume that the populations are evenly distributed, and also non-residential areas, those who are not directly adjacent to highways, are also counted as being exposed to degraded air quality. If, for example, a CBG (or tract) is adjacent to a highway, yet has a highly distributed population, all of the people in that CBG will be considered to have equal exposure which, in most cases, will not be accurate since distances greater than $150 \mathrm{~m}$ from the highway may not experience the same level of exposure as those immediately adjacent, that is, less than $150 \mathrm{~m}$. When applying a tax lot-derived exposure estimate only those living adjacent to the highway (in this case 75, and $150 \mathrm{~m}$ ) will be counted as potentially exposed. We posit that such differences are not trivial because they provide an accurate description of who is impacted by mobile sources of air pollution, and offer mitigation opportunities for targeting area where long-term exposure can lead to detrimental impacts on human health and well-being.

Our results suggest a need to examine three inter-connected dimensions for reducing potential exposure to degraded air quality. First, characterizing the distribution of communities in urban landscapes requires greater scrutiny. One of the primary sources for population information in the United States is the Census, which is required by the constitution to be conducted every ten years. The U.S. Census has created a hierarchy of geographies-smallest is the block-with the population as the only consistent feature within each of the increasingly larger areas. Assumed within each geographic extent is the uniform distribution of individuals, which as our CIDs approach illustrates is not effective in understanding or characterizing environmental injustices. Moreover, our approach to identify MFR required developing an algorithm based on land values, and validating through individual phone calls. While time-intensive, such approaches are currently the only way to develop population distribution estimates for a heterogeneous land use mix. Needed are population distributions that take into account the land uses throughout a region. Several countries, including China, Germany, and England, have national land use datasets, which provides the foundation for applying our CIDS approach to other cities with nationally consistent land use systems.

Second, the field of exposure studies is undergoing a renaissance, with new journals, conferences, and projects emerging throughout the world. Essential for advancing the field of exposure studies is empirically derived environmental quality information. The present study has the advantage of building on earlier assessments of $\mathrm{NO}_{2}$ concentrations, which are generally not available at our resolution for most cities and regions. By identifying and integrating places in the region with the worst air quality, and containing the most numbers of people, we can more accurately describe 'hot spots' for potential exposure. One limitation is that we only used one air pollutant $\left(\mathrm{NO}_{2}\right)$, and a more comprehensive approach would identify particulate matter and/or black carbon, which have far-reaching consequences on human health. The emergence of several off-the-shelf air quality measurements systems offer several opportunities for integrating high-resolution description of environmental quality with the distribution of populations. Our approach provides an effective approach to addressing social vulnerability within the field of exposure studies. 
Finally, environmental justice literature is replete with description of communities that are disproportionately burdened with harmful air pollutants, yet missing from these studies are examples of approaches for identifying effective mitigation strategies. We attempted to use a modeling approach to describe the implication of a tree planting strategy to improve degraded air quality. By combining a spatially-explicit description of tree planting efforts with estimations for future vegetation growth, we created a model for evaluating the beneficiaries of such campaigns. As a result, rather than opportunistic application of urban canopy campaigns, our approach can enable natural resource managers, urban planners, and public health practitioners to strategically identify locations where air quality improvements are needed. While empirical validation of our assumptions for air quality improvements are needed, this approach offers a timely and systematic evaluation framework for committing resources to canopy campaigns.

Implications for Urban Health and Well-Being

Regulatory frameworks for addressing air pollution at the national and regional levels may obscure, or worse, completely miss, those most impacted by poor air. By integrating highly-resolved air quality data with residential locations, we identify locations, such as near freeways, where communities are likely experiencing harmful health outcomes. While our analysis does not directly assess exposure-rather, we use ambient concentrations of $\mathrm{NO}_{2}$ as a measure-a first step is to develop accurate descriptions about who and where degraded air quality is most likely to create adverse human health impacts.

In the PMA we can expect, based on findings in the US and other developed nations, that populations exposed to the most degraded air quality may also lack the resources to combat the health impacts of air pollution, as they tend to have lower median household income and are more likely to be transient [46-49]. To that end, our results suggest a need for engaging both city planners and community groups in improving local air quality. The management of air quality in the US occurs at the regional or state jurisdictions and local decision-makers are not immediately charged with addressing degraded environmental conditions. Moreover, local decision-makers often lack access to data at the necessary spatial resolution to make effective decisions. Nevertheless, many cities are looking to improve local air quality through using climate action plans [50,51] and receiving help from federal agencies to pursue such efforts (see for example: US Environmental Protection Agency's report entitled, "Air, Climate, and Energy Strategic Research Action Plan, 2012-2016").

Urban air pollution typically consists of highly reactive and highly spatially variable pollutants such as $\mathrm{NO}_{2}$, ozone, and fine particulate matter. While national interest in addressing environmental justice is growing the current state of the science needs a greater focus on integrating highly-resolved datasets. The Environmental Protection Agency, for example, has recently released an EJScreen ${ }^{\mathrm{TM}}$ for "environmental justice mapping and screening ... that provides ... a nationally consistent dataset and approach for combining environmental and demographic indicators," which continues to rely on CBG, tract, and larger geographies for identifying specific communities at risk from degraded air quality. While such tools are helpful for national or state level assessments of environmental justice, local communities often require greater specificity (and resolution) for taking mitigation actions.

New techniques that combine observational data with modeling - such as Land Use Regression (LUR) and Congestion Mitigation and Air Quality (CMAQ) — are emerging, and have the potential to provide spatially-explicit data for assessing finer, local-scale air pollution. However, without highly-resolved descriptions of the distribution of the urban population, we cannot identify those most exposed to degraded air quality and, hence, have little impact on the management of environmental determinants of human health. Given the ready availability of land use tax lot data and increasingly resolved air quality data, our approach offers a relatively seamless and accurate diagnostic approach for identifying locations where mitigation of air pollution needs immediate and sustained attention.

In addition, at the neighborhood level, community groups are also highly engaged with improving local air quality. Groups in California, New York, Colorado, and other US states are working directly 
with state and local health officials to begin assessing the implications of improving neighborhood air quality. One notable example is a group in Oregon called Neighbors for Clean Air, which has mobilized community members, non-profit organizations, the scientific community, and government agencies in improving air quality for neighborhoods in Portland, Oregon [52]. Having spatially-resolved data can be essential to empowering local groups to take action, since many current policies for managing air quality reside at state and national levels.

\section{Conclusions}

The design of cities that support human habitation requires at once the capacity to know those areas that are currently burdened with disproportionate environmental pollution, and understanding the role of short and long-term mitigation efforts. One of the main objectives of the present paper is to evaluate the differences in potential exposure among three different geographies. We developed a novel technique that integrates existing, highly-resolved air quality data with highly-resolved distribution of populations within one metropolitan area. We found that high-resolution descriptions of air quality and population distributions offer many advantages to describing the number of people impacted by degraded environmental conditions, with greater differences when examining specific areas, versus entire metropolitan regions. We also evaluated the extent to which tree-planting efforts can improve air quality for communities. By examining areas where these tree-planting efforts can improve air quality, we also provide a systematic approach to evaluating the beneficiaries of such campaigns.

The results support an emerging area of exposure science, which is beginning to provide epidemiological evidence about human health outcomes from degraded environmental conditions [53]. The exposure science literature provides further evidence that tree-plantings at the scale of the city block are effective in improving air quality [54-56]. While our CIDS approach does not describe actual exposure-which itself is mediated through complex mechanisms of travel behavior and other activities-it does offer a first step to understanding how humans are potentially impacted by ambient air pollution.

We also note that several municipalities are pursing green infrastructure projects as a means for mitigating air pollution. A recent example in the Seattle area, describes a coalition that is developing green infrastructure projects in the Lower Duamish-already a highly-polluted and lower-income population-that aim to improve air quality. Countless other examples illustrate community involvement in tree-planting efforts, many of which aim to improve the social and environmental conditions of historically marginalized neighborhoods. Our analysis provides support for urban tree-planting projects by further explicating the spatial distribution of benefits and burdens that associate to these efforts. This study goes further, however, to also argue that high-resolution descriptions about the co-location of urban tree-planting efforts, densities, and socio-demographics, is essential for reducing the social and environmental inequities that befall those who have the least access to resources.

Arguably, the need to improve the resolution of air quality data is consistent with developing spatially-explicit approach to address mitigation strategies. From the perspective of human health and well-being, developing approaches that are directly relevant to existing planning and decision-making efforts is essential. Since air quality management in the US is largely the purview of federal air quality regulations, local planning bureaus have little authority for improving public health and safety in terms of ambient air quality. We posit that one challenge facing municipal decision-makers is identifying priority areas for addressing mitigation efforts. For example, since cities are constantly developing and modifying landscapes through permitting developments, identifying areas that are highly degraded, provides municipal managers with evidence for requiring mitigation efforts before allowing new (or re-) construction. Since land use planning occurs at the tax lot scale, our CIDS approach is one cost-effective and timely approach to assessing, and identifying, communities that are disproportionately impacted by poor air quality. These methods are one part of a broader agenda at 
enabling local communities to regulate pollutants, and mitigate their impact on those communities who have been historically burdened by degraded air.

Acknowledgments: We acknowledge several individuals and organizations that provided support for the present study. Individuals include Sam Baraso who currently works for the Office of Sustainability at Multnomah County (Oregon) and supported the spatial analysis and data procurement for this project. Also, Bobby Cochran of Willamette Partnership contributed ideas and helped the research team to meet members at and work with Clean Water Services on this project. We also thank Mac Martin at Clean Water Services who provided data of tree-plantings. For financial assistance on this project, we are grateful to the United States Forest Service's Urban and Community Forestry program (2011-DG-11062765-016), and the Institute for Sustainable Solutions at Portland State University. Without these individuals and organizations, we could not have completed this research project.

Author Contributions: V.S. and J.V. conceived and designed the analysis; V.S. and J.V. analyzed the results; L.G. and M.R. contributed data and consulted on air quality; V.S., J.V., and M.R. wrote the paper.

Conflicts of Interest: The authors declare no conflict of interest.

\section{References}

1. Künzli, N.; Kaiser, R.; Medina, S.; Studnicka, M.; Chanel, O.; Filliger, P.; Herry, M.; Horak, F.; Puybonnieux-Texier, V.; Quénel, P.; et al. Public-health impact of outdoor and traffic-related air pollution: A European assessment. Lancet 2000, 356, 795-801. [CrossRef]

2. Muller, N.; Mendelsohn, R.; Nordhaus, W. Environmental Accounting for Pollution in the United States Economy. Am. Econ. Rev. 2011, 101, 1649-1675. [CrossRef]

3. Fann, N.; Lamson, A.D.; Anenberg, S.C.; Wesson, K.; Risley, D.; Hubbell, B.J. Estimating the national public health burden associated with exposure to ambient $\mathrm{PM}_{2.5}$ and ozone. Risk Anal. 2012, 32, 81-95. [CrossRef] [PubMed]

4. Brook, R.D.; Rajagopalan, S.; Pope, C.A.; Brook, J.R.; Bhatnagar, A.; Diez-Roux, A.V. Particulate matter air pollution and cardiovascular disease: An update to the scientific statement from the American Heart Association. Circulation 2010, 121, 2331-2378. [CrossRef] [PubMed]

5. Wilker, E.H.; Preis, S.R.; Beiser, A.S.; Wolf, P.A.; Au, R.; Kloog, I.; Li, W.; Schwartz, J.; Koutrakis, P.; DeCarli, C.; et al. Long-Term Exposure to Fine Particulate Matter, Residential Proximity to Major Roads and Measures of Brain Structure. Stroke 2015, 46, 1161-1166. [CrossRef] [PubMed]

6. Korek, M.J.; Bellander, T.D.; Lind, T.; Bottai, M.; Eneroth, K.M.; Caracciolo, B.; Penell, J.C. Traffic-related air pollution exposure and incidence of stroke in four cohorts from Stockholm. J. Expo. Sci. Environ. Epidemiol. 2015, 25, 517-523. [CrossRef] [PubMed]

7. Beelen, R.; Hoek, G.; Vienneau, D.; Eeftens, M.; Dimakopoulou, K.; Pedeli, X.; Tsai, M.Y.; Künzli, N.; Schikowski, T.; Marcon, A.; et al. Development of $\mathrm{NO}_{2}$ and $\mathrm{NOx}$ land use regression models for estimating air pollution exposure in 36 study areas in Europe-The ESCAPE project. Atmos. Environ. 2013, 72, 10-23. [CrossRef]

8. Jerrett, M.; Arain, A.; Kanaroglou, P.; Beckerman, B.; Potoglou, D.; Sahsuvaroglu, T.; Morrison, J.; Giovis, C. A review and evaluation of intraurban air pollution exposure models. J. Expo. Anal. Environ. Epidemiol. 2005, 15, 185-204. [CrossRef] [PubMed]

9. Stuart, A.L.; Mudhasakul, S.; Sriwatanapongse, W. The Social Distribution of Neighborhood-Scale Air Pollution and Monitoring Protection. J. Air Waste Manag. Assoc. 2009, 59, 591-602. [CrossRef] [PubMed]

10. Mavko, M.E.; Tang, B.; George, L.A. A sub-neighborhood scale land use regression model for predicting NO. Sci. Total Environ. 2008, 398, 68-75. [CrossRef] [PubMed]

11. Lemke, L.D.; Lamerato, L.E.; Xu, X.; Booza, J.C.; Reiners, J.J.; Raymond, D.M., III; Villeneuve, P.J.; Lavigne, E.; Larkin, D.; Krouse, H.J. Geospatial relationships of air pollution and acute asthma events across the Detroit-Windsor international border: Study design and preliminary results. J. Expo. Anal. Environ. Epidemiol. 2014, 24, 346-357. [CrossRef] [PubMed]

12. Shandas, V.; George, L.A. Spatial patterns of air toxins in the region. In Periodic Atlas of the Metroscape; College of Urban and Public Affairs, Portland State University: Portland, OR, USA, 2009.

13. Clark, L.P.; Millet, D.B.; Marshall, J.D. Air quality and urban form in U.S. urban areas: Evidence from regulatory monitors. Environ. Sci. Technol. 2011, 45, 7028-7035. [CrossRef] [PubMed]

14. Clougherty, J.E.; Wright, R.J.; Baxter, L.K.; Levy, J.I. Land use regression modeling of intra-urban residential variability in multiple traffic-related air pollutants. Environ. Health 2008. [CrossRef] [PubMed] 
15. Rowangould, G.M. A census of the US near-roadway population: Public health and environmental justice considerations. Trans. Res. Part D 2013, 25, 59-67. [CrossRef]

16. Brulle, R.J.; Pellow, D.N. Environmental justice: Human health and environmental inequalities. Annu. Rev. Public Health 2006, 27, 103-124. [CrossRef] [PubMed]

17. O'Neill, M.S.; Jerrett, M.; Kawachi, I.; Levy, J.I.; Cohen, A.J.; Gouveia, N. Health, wealth, and air pollution: Advancing theory and methods. Environ. Health Perspect. 2003, 111, 1861-1870. [CrossRef] [PubMed]

18. Duh, J.-D.; Shandas, V.; Chang, H.; George, L.A. Rates of urbanisation and the resiliency of air and water quality. Sci. Total Environ. 2008, 400, 238-256. [CrossRef] [PubMed]

19. Pickett, S.T.A.; Boone, C.G.; McGrath, B.P.; Cadenasso, M.L.; Childers, D.L.; Ogden, L.A.; Grove, J.M. Ecological science and transformation to the sustainable city. Cities 2003, 32 (Suppl. 1), S10-S20. [CrossRef]

20. Hoek, G.; Beelen, R.; de Hoogh, K.; Vienneau, D.; Gulliver, J.; Fischer, P.; Briggs, D. A review of land-use regression models to assess spatial variation of outdoor air pollution. Atmos. Environ. 2008, 42, 7561-7578. [CrossRef]

21. Jerrett, M.; Shankardass, K.; Berhane, K.; Gauderman, W.J.; Künzli, N.; Avol, E.; Gilliland, F.; Lurmann, F.; Molitor, J.N.; Molitor, J.T.; et al. Traffic-related air pollution and asthma onset in children: A prospective cohort study with individual exposure measurement. Environ. Health Perspect. 2008, 116, 1433-1438. [CrossRef] [PubMed]

22. Fann, N.; Fulcher, C.M.; Hubbell, B.J. The influence of location, source, and emission type in estimates of the human health benefits of reducing a ton of air pollution. Air Qual. Atmos. Health 2009, 2, 169-176. [CrossRef] [PubMed]

23. Nowak, D.J.; Hirabayashi, S.; Bodine, A.; Hoehn, R. Modeled $\mathrm{PM}_{2.5}$ removal by trees in ten U.S. cities and associated health effects. Environ. Pollut. 2013, 178, 395-402. [CrossRef] [PubMed]

24. Hubbell, B.J.; Hallberg, A.; McCubbin, D.R.; Post, E. Health-Related Benefits of Attaining the 8-Hr Ozone Standard. Environ. Health Perspect. 2004, 113, 73-82. [CrossRef]

25. Eeftens, M.; Beelen, R.; de Hoogh, K.; Bellander, T.; Cesaroni, G.; Cirach, M.; Declercq, C.; Dẻdelè, A.; Dons, E.; de Nazelle, A.; et al. Development of Land Use Regression models for PM(2.5), PM(2.5) absorbance, PM(10) and PM(coarse) in 20 European study areas; results of the ESCAPE project. Environ. Sci. Technol. 2012, 46, 11195-11205. [CrossRef] [PubMed]

26. Steinle, S.; Reis, S.; Sabel, C.E. Quantifying human exposure to air pollution-Moving from static monitoring to spatio-temporally resolved personal exposure assessment. Sci. Total Environ. 2013, 443, 184-193. [CrossRef] [PubMed]

27. Kumar, P.; Sabatino, S.D.; Morawska, L.; Bell, M.; Martani, C.; Norford, L.; Biskos, G.; Britter, R. The rise of low-cost sensing for managing air pollution in cities. Environ. Int. 2015, 75, 199-205. [CrossRef] [PubMed]

28. Maantay, J.A.; Maroko, A.R.; Herrmann, C. Cartography and Geographic Information Science; Taylor \& Francis Group: Abingdon, UK, 2007; Volume 34, pp. 77-102.

29. Mennis, J.L.; Jordan, L. The Distribution of Environmental Equity: Exploring Spatial Nonstationarity in Multivariate Models of Air Toxic Releases. Ann. Assoc. Am. Geogr. 2005, 95, 249-268. [CrossRef]

30. Bowen, W. An analytical review of environmental justice research: What do we really know? Environ. Manag. 2002, 29, 3-15. [CrossRef]

31. Schweitzer, L.; Stephenson, M. Right Answers, Wrong Questions: Environmental Justice as Urban Research. Urban Stud. 2007, 44, 319-337. [CrossRef]

32. Walker, G. Environmental justice, impact assessment and the politics of knowledge: The implications of assessing the social distribution of environmental outcomes. Environ. Impact Assess. Rev. 2010, 30, 312-318. [CrossRef]

33. Forastiere, F.; Peters, A.; Kelly, F.J.; Holgate, S.T. Nitrogen dioxide. In Air Quality Guidelines: Global Update 2005. Particulate Matter, Ozone, Nitrogen Dioxide and Sulfur Dioxide; World Health Organization: Copenhagen, Denmark, 2006; pp. 331-394.

34. Finlayson-Pitts, B.J.; Pitts, J.N. Chemistry of the Upper and Lower Atmosphere: Theory, Experiments and Applications; Academic Press: San Diego, CA, USA, 2000.

35. Seinfeld, J.H.; Pandis, S.N. Atmospheric Chemistry and Physics: From Air Pollution to Climate Change; John Wiley \& Sons, Inc.: Hoboken, NJ, USA, 1998.

36. Karner, A.A.; Eisinger, D.S.; Niemeier, D.A. Near-roadway air quality: Synthesizing the findings from real-world data. Environ. Sci. Technol. 2010, 44, 5334-5344. [CrossRef] [PubMed] 
37. Rao, M.; George, L.A.; Rosenstiel, T.N.; Shandas, V.; Dinno, A. Assessing the relationship among urban trees, nitrogen dioxide, and respiratory health. Environ. Pollut. 2014, 194, 96-104. [CrossRef] [PubMed]

38. McConnell, R.; Berhane, K.; Yao, L.; Jerrett, M.; Lurmann, F.; Gilliland, F.; Künzli, N.; Gauderman, J.; Avol, E.; Thomas, D.; et al. Traffic, Susceptibility, and Childhood Asthma. Environ. Health Perspect. 2006, 114, 766-772. [CrossRef] [PubMed]

39. Perez, L.; Lurmann, F.; Wilson, J.; Pastor, M.; Brandt, S.J.; Künzli, N.; McConnell, R. Near-Roadway Pollution and Childhood Asthma: Implications for Developing “Win-Win" Compact Urban Development and Clean Vehicle Strategies. Environ. Health Perspect. 2012, 120, 1619-1626. [CrossRef] [PubMed]

40. Gauderman, W.J. Effect of Exposure to Traffic on Lung Development from 10 to 18 Years of Age: A Cohort Study. Lancet 2007, 369, 571-577. [CrossRef]

41. Brugge, D. Near-Highway Pollutants in Motor Vehicle Exhaust: A Review of Epidemiologic Evidence of Cardiac and Pulmonary Health Risks. Environ. Health A Glob. Access Sci. Source 2007. [CrossRef] [PubMed]

42. McPherson, E.G.; Paula, J.P. Urban tree growth modeling. Arboric. Urban For. 2012, 38, 175-183.

43. Eicher, C.L.; Brewer, C.A. Dasymetric Mapping and Areal Interpolation: Implementation and Evaluation. Cartogr. Geogr. Inf. Sci. 2001, 2, 125-138. [CrossRef]

44. Brauer, M.; Hoek, G.; Smit, H.; de Jongste, J.C.; Gerritsen, J.; Postma, D.S.; Kerkhof, M.; Brunekreef, B. Air pollution and development of asthma, allergy and infections in a birth cohort. Eur. Respir. J. 2007, 29, 879-888. [CrossRef] [PubMed]

45. Ostro, B.; Lipsett, M.; Mann, J.; Braxton-Owens, H.; White, M. Air pollution and exacerbation of asthma in African-American children in Los Angeles. Epidemiology 2001, 12, 200-208. [CrossRef] [PubMed]

46. Briggs, D.; Abellan, J.J.; Fecht, D. Environmental Inequity in England: Small Area Associations between Socio-Economic Status and Environmental Pollution. Soc. Sci. Med. 2008, 67, 1612-1629. [CrossRef] [PubMed]

47. Carrier, M.; Apparicio, P.; Seguin, A.M.; Crouse, D. The Application of Three Methods to Measure the Statistical Association between Different Social Groups and the Concentration of Air Pollutants in Montreal: A Case of Environmental Equity. Transp. Res. Part D Transp. Environ. 2014, 30, 38-52. [CrossRef]

48. Crouse, D.L.; Goldberg, M.S.; Ross, N.A. A Prediction-Based Approach to Modelling Temporal and Spatial Variability of Traffic-Related Air Pollution in Montreal, Canada. Atmos. Environ. 2009, 43, 5075-5084. [CrossRef]

49. Kingham, S.; Pearce, J.; Zawar-Reza, P. Driven to Injustice? Environmental Justice and Vehicle Pollution in Christchurch, New Zealand. Transp. Res. Part D Transp. Environ. 2007, 12, 254-263. [CrossRef]

50. Bassett, E.; Shandas, V. Innovation in Municipal Climate Planning. J. Am. Plan. Assoc. 2010, 76, 435-450. [CrossRef]

51. Boswell, M.R.; Greve, A.I.; Seale, T.L. An Assessment of the Link between Greenhouse Gas Emissions Inventories and Climate Action Plans. J. Am. Plan. Assoc. 2010, 76, 451-462. [CrossRef]

52. Driessen, K. Neighbors for Clean Air Files Intent to Sue Intel over Alleged Clean Air Action Violations in Hillsboro. The Oregonian/OregonLive 2013. Available online: http:/ /www.oregonlive.com/hillsboro/ index.ssf /2013/10/intels_air_quality_neighbors_f.html (accessed on 22 October 2013).

53. Morello-Frosch, R.; Shenassa, E.D. The environmental "riskscape" and social inequality: Implications for explaining maternal and child health disparities. Environ. Health Perspect. 2006, 114, 1150-1153. [CrossRef] [PubMed]

54. Salmond, J.A.; Williams, D.E.; Laing, G.; Kingham, S.; Dirks, K.; Longley, I.; Henshaw, G.S. The influence of vegetation on the horizontal and vertical distribution of pollutants in a street canyon. Sci. Total Environ. 2013, 443, 287-298. [CrossRef] [PubMed]

55. Setala, H.; Vippola, V.; Rantalainen, A.L.; Pennanen, A.; Yli-Pelkonen, V. Does urban vegetation mitigate air pollution in northern conditions? Environ. Pollut. 2012, 183, 104-112. [CrossRef] [PubMed]

56. Selmi, W.; Weber, C.; Riviere, E.; Blond, N.; Mehdi, L.; Nowak, D. Air pollution removal by trees in public green spaces in Strasbourg city, France. Urban For. Green 2016, 17, 192-201. [CrossRef]

(C) 2016 by the authors; licensee MDPI, Basel, Switzerland. This article is an open access article distributed under the terms and conditions of the Creative Commons Attribution (CC-BY) license (http:/ / creativecommons.org/licenses/by/4.0/). 